\title{
Modified tuber starches as potential stabilizer for food-grade Pickering emulsions
}

\author{
${ }^{1}$ Xian, L.X., ${ }^{1}$ Shariffa, N.Y., ${ }^{2}$ Azwan, M.L. and ${ }^{1 *}$ Uthumporn Utra \\ ${ }^{1}$ Food Technology Division, School of Industrial Technology, Universiti Sains Malaysia, Penang, Malaysia \\ ${ }^{2}$ School of Chemical Sciences and Food Technology, Universiti Kebangsaan Malaysia, Selangor, Malaysia
}

\begin{abstract}
Article history:
Received: 25 October 2019

Received in revised form: 27 December 2019

Accepted: 29 December

2019

Available Online: 27 January 2020
\end{abstract}

\section{Keywords:}

Hydrophobic modification,

Hydroxypropylation,

OSA modification,

Pickering emulsions,

Thermal modification,

Tuber starch particles

DOI:

https://doi.org/10.26656/fr.2017.4(3).351

\begin{abstract}
The application of modified tuber starches in particle-stabilized emulsions was studied to obtain surfactant-free emulsions, called Pickering emulsions. Three different starches, namely, potato $(\mathrm{P})$, sweet potato $(\mathrm{S})$ and tapioca $(\mathrm{T})$ starches were modified using dry-heat treatment $\left(\mathrm{HD}, 120^{\circ} \mathrm{C}, 150 \mathrm{mins}\right)$, hydrothermal treatment $\left(\mathrm{HM}, 50^{\circ} \mathrm{C}, 30 \mathrm{mins}\right)$, OSAmodification (OSA, 2.9\%) and hydroxypropylation (HP, $2 \mathrm{~mL}$ of $20 \%$ propylene oxide) before being used as stabilizer for stabilizing emulsion. The physicochemical properties of the starches and the characteristics of the stabilized emulsion were studied. Potato OSAtreated starch (POSA) had significantly higher degree of substitution (DS) $(\mathrm{DS}=0.0154)$ than SOSA (DS $=0.0081$ ) and TOSA ( $\mathrm{DS}=0.0083$ ). For the starches undergone treatment of hydroxypropylation, SHP had the highest molar substitution (MS) value of 0.20 , followed by PHP (0.11) and THP (0.10). The amylose content of starches reduced significantly after all modifications (HD, HM, OSA, and HP). All OSA-treated starch (POSA, SOSA, and TOSA) had higher fat binding capacity compared to their native and starches that modified using different treatments (HD, HM, and HP). Based on the emulsification index values and optical microscopic images, all starch particles were able to stabilize emulsions except for SC, SHM, TC, and THM. Optical microscopic images showed that the starch particles accumulated and formed a densely packed layer at the oilwater interface. At the starch concentration of $400 \mathrm{mg} / \mathrm{mL}$ oil, emulsion stabilized by dryheated potato starch and all hydroxypropylated-starch-stabilized emulsions had a high emulsification index value of 1 . Significantly highest viscosity was noticed from the emulsion stabilized by POSA. Overall, by comparing the physico-chemical properties of the modified starches and the characteristics of emulsions stabilized, potato OSA-treated starch (POSA) had the best emulsifying ability.
\end{abstract}

\section{Introduction}

Emulsion systems can be found in both food products (milk, butter, mayonnaise, and salad dressings) and non-food products (cosmetics and pharmaceutical products). There are two main types of emulsions, oil-inwater $(\mathrm{O} / \mathrm{W})$ and water-in-oil $(\mathrm{W} / \mathrm{O})$. Emulsions are formed when the interfacial surface tension between the two immiscible phases is reduced and repulsive steric hindrances were generated between the droplets, causing one phase dispersed as droplets in another. Surfactants, proteins, and hydrocolloids are commonly used as an emulsifier in food emulsions (Timgren et al., 2013). However, some emulsifiers may contain residual allergens, for example, milk, egg, soy lecithins, Tragacanth (E413), Acacia gum (E414), Karaya gum (E416), Mannitol (E421) and gelatin (E441) (Gelfand,
1943; Hannuksela et al., 1976; Sakaguchi et al., 1996; Palm et al., 1999; Friberg et al., 2003). Besides, the permitted level of emulsifier in food is relatively low and the amount might not enough to maintain a stable emulsion (McClements, 2015). As an example, according to the EU standards, polyglycerol esters of fatty acids (E475) which commonly used in fat and oil emulsions (butter, margarine and spreads) is only permitted to use with a maximum limit of $5000 \mathrm{mg} / \mathrm{kg}$. Therefore, studies to obtain surfactant-free emulsions, such as Pickering emulsions (also called as particlestabilized emulsions) are extensively been studied (Pickering, 1907; Rayner et al., 2012; Timgren et al., 2013; Song et al., 2015).

Pickering emulsions are known for their ability to display long-term stability without the addition of 
surfactant. Solid particles are utilized alone in Pickering emulsions as stabilizers, by attaching themselves to the oil-water interface, irreversibly, providing a higher stabilization than surfactant adsorption (Pickering, 1907). Pickering emulsions are more stable against coalescence and Ostwald ripening compared to emulsion stabilized by surfactants (Rayner et al., 2012). In contrast to particles commonly used for Pickering emulsions (silica, alumina, wax, chitin, clay particles and titanium oxides), hydrophobically modified starch with small granule size and regular shape was found more suitable to be used for stabilizing $\mathrm{O} / \mathrm{W}$ emulsions (Song et al., 2015).

Starch was found suitable to be used as an emulsifier in their gelatinized form or mechanically fractured form or combination with protein (Murray et al., 2011; Yusoff and Murray, 2011). The advantages of using starch to replace surfactant are: starch is an acceptable food ingredient and pharmaceutical excipient, it can be easily obtained from various botanical sources, is abundant, inexpensive, biodegradable, and non-toxic (Song et al., 2015). However, starch in their native form is not hydrophobic in nature, and hence not suitable to be used as emulsion stabilizer because of its inability to adsorb to the oil-water interface. Nevertheless, the hydrophobicity of starch can be increased by chemical or physical modification. In this study, tuber starches such as potato (Solanum tuberosum), sweet potato (Ipomoea batatas), and tapioca starch (Manihot esculenta) were selected for modification.

One of the most common ways to chemically modify starch is by esterification treatment with different alkenyl succinyl anhydrides, such as, octenyl succinic anhydride (OSA), which has been approved for food applications at an added amount of up to 3\% based on the dry weight of starch (Sweedman et al., 2013). The hydrophobic octenyl group and the carboxyl group will increase the affinity of starch to oil (Timgren et al., 2013). By using propylene oxide as an etherifying agent, hydroxyl group of starch is substituted with hydroxypropyl group, thereby producing hydroxypropyl starch, with emulsifying properties (Mitchell et al., 1977). Hydroxypropyl starch with molar substitution (MS) value not more than 0.2 is approved by US FDA for food applications (Dias et al., 1997). The hydrophobicity of starch can also be enhanced by physical method such as dry heating. Dry heating will modify the surface proteins of starch granule from hydrophilic to hydrophobic (Seguchi, 1984). This thermal modification has several advantages, where no limitation on the modification for food applications, hydrophobic alteration is explicitly occurring at the granule surface and the method is very simple (Timgren et al., 2013).
This study focused on the effect of modifications namely, dry-heat treatment, hydrothermal treatment, OSA-modification and hydroxypropylation on the properties and emulsifying ability of tuber starches including potato, sweet potato, and tapioca. Previously, there was not much research related to OSA modification conducted on tuber starch. Maize and waxy maize starches were mainly used in most of the research (Sweedman et al., 2013). The objective of this study was to examine the physico-chemical properties and emulsifying capacity of the native and modified tuber starches.

\section{Materials and methods}

\subsection{Materials}

Potato starch and tapioca starch were obtained from Billion hypermarket (Penang, Malaysia) while sweet potato starch was obtained from Hock Huat Flour Specialist Sdn. Bhd. (Penang, Malaysia). OSA was purchased from Tokyo Chemical Industry Co., Ltd. Propylene oxide was obtained from Sigma Aldrich, Darmstadt, Germany. All other chemicals and reagents used in this work were of analytical grade.

\subsection{Starch modification}

\subsubsection{Dry-heat treatment}

The dry-heat treatment was performed based on the method described by Seguchi (1984). Dry starch (50 g, dry basis) was placed in opened moisture dishes in a 1 $2 \mathrm{~mm}$ thick layer and heated at $120^{\circ} \mathrm{C}$ for 150 mins. The heated starch was cooled at room temperature for $2 \mathrm{hrs}$.

\subsubsection{Hydrothermal treatment (mild annealing)}

Starch was added to $100 \mathrm{~mL}$ of water $(25 \% \mathrm{w} / \mathrm{v})$ and incubated in a water bath at $50^{\circ} \mathrm{C}$ for 30 mins with continuous stirring using an overhead stirrer. After 30 mins, the starch slurry was then washed immediately with distilled water and filtered. The samples were dried at $40^{\circ} \mathrm{C}$ for $48 \mathrm{hrs}$ and grounded into powder.

\subsubsection{OSA-modification of starch}

OSA-modified starch was prepared based on the methods described by Rayner et al. (2012) and Timgren et al. (2013) with slight modification. Starch (50 g, dry basis) was thoroughly suspended in water using a stainless-steel propeller and the $\mathrm{pH}$ was adjusted to 7.6 using $25 \% \mathrm{HCl}$ and/or $1 \mathrm{M} \mathrm{NaOH}$. OSA $(2.9 \%$ based on the dry weight of the starch) was added in four equal portions at intervals of 15 mins. The $\mathrm{pH}$ value was maintained at 7.6 during the treatment. The treatment was considered to be completed when the $\mathrm{pH}$ was constant for at least 15 mins. The mixture of starch and water was centrifuged at $3000 \times \mathrm{g}$ for 10 mins and the 
supernatant was removed. The starch was resuspended and centrifuged, twice with distilled water and once with citric acid ( $\mathrm{pH}$ 4.5). The OSA-modified and washed starch granules were spread on stainless steel trays and dried at room temperature for at least $48 \mathrm{hrs}$.

\subsubsection{Degree of substitution measurement}

The degree of OSA substitution was determined using a titration method with slight modification (Rayner et al., 2012). The analyses were performed in triplicate for both the OSA-modified starch and the control starch. OSA-modified starch ( $2.5 \mathrm{~g}$, dry basis) was dispersed in $25 \mathrm{~mL}$ of $0.1 \mathrm{M} \mathrm{HCL}$ and stirred with a magnetic stirrer for 30 mins before centrifugation at $3000 \times \mathrm{g}$ for 10 mins. The starch was washed once with $25 \mathrm{~mL}$ of ethanol $(90 \%)$ and twice with distilled water. The starch was suspended in $300 \mathrm{~mL}$ water and heated in a water bath at $95^{\circ} \mathrm{C}$ for 10 mins before being cooled to $25^{\circ} \mathrm{C}$. The gelatinized starch mixture was then titrated with 0.1 $\mathrm{M} \mathrm{NaOH}$ until the $\mathrm{pH}$ reached 8.3. A blank was simultaneously titrated with native starch of the same origin as the OSA starch as a sample. The percentage of OSA substitution and the degree of substitution were calculated by

$$
\text { OSA substitution }(\%)=\frac{(\text { Vsample }- \text { Vcontrol }) \cdot \mathrm{M} \cdot 210}{\mathrm{~W}} \times 100 \%
$$

Where $\mathrm{V}$ is the volume $(\mathrm{mL})$ of $\mathrm{NaOH}$ required for the sample and the blank titration, $\mathrm{M}$ is the molarity of $\mathrm{NaOH}(0.1 \mathrm{M}), \mathrm{W}$ is the dry weight of the starch $(\mathrm{mg})$, and 210 is the molecular weight of octenyl succinate group

$$
\text { Degree of Substitution (DS) }=\frac{162 \times \text { OSA substitution (\%) }}{21000-[209 \times \text { OSA substitution (\%) }]}
$$

Where 162 is the molecular weight of the glucose unit, 21000 is $100 \times$ molecular weight of octenyl succinate group, and 209 is the molecular weight of octenyl succinate group minus the molecular weight of hydrogen atom

\subsubsection{Hydroxypropylation of starch}

Hydroxypropyl starch was prepared according to the method described by Lawal (2011) with slight modification. Starch (50 g, dry basis) was weighed into $250 \mathrm{~mL}$ Schott glass bottle followed by $75 \mathrm{~mL}$ of distilled water and $7.5 \mathrm{~g}$ of sodium sulphate $\left(\mathrm{Na}_{2} \mathrm{SO}_{4}\right)$. The slurry was incubated in the orbital shaker SI-600R (JEIO Tech, Seoul, Korea) at room temperature $\left(25^{\circ} \mathrm{C}\right)$ with the speed of $150 \mathrm{rpm}$ for $40 \mathrm{mins}$. The $\mathrm{pH}$ value of the slurry was adjusted to $\mathrm{pH} 11$ with sodium hydroxide $(\mathrm{NaOH})(1 \mathrm{~mol} / \mathrm{L})$ followed by the addition of $2 \mathrm{~mL}$ of propylene oxide $(20 \%)$. The flask was then capped and incubated for 30 mins at room temperature with the speed of $150 \mathrm{rpm}$ in an incubator shaker SI-600R (JEIO
Tech, Seoul, Korea). The reaction was maintained at $40^{\circ} \mathrm{C}$ for $24 \mathrm{hrs}$ with the speed of $200 \mathrm{rpm}$. The starch suspension was neutralized with dilute hydrochloric acid $(\mathrm{HCl})(0.1 \mathrm{~mol} / \mathrm{L})$ and washed immediately with distilled water and filtered. The samples were dried at $40^{\circ} \mathrm{C}$ for 2 days and grounded into powder.

\subsubsection{Determination of molar substitution}

The presence of hydroxypropyl groups in modified starch was performed according to the method proposed by Johnson (1969). Hydroxypropyl starch (100 mg, dry basis) was weighed into a $100 \mathrm{~mL}$ volumetric flask and $25 \mathrm{~mL}$ of sulphuric acid $(0.5 \mathrm{~mol} / \mathrm{L})$ was added. The flask was placed and heated in a boiling water bath until a clear solution was obtained. About $1 \mathrm{~mL}$ of the solution was pipetted into $25 \mathrm{~mL}$ volumetric flask, immersed in cold water and $8 \mathrm{~mL}$ of concentrated sulphuric acid was added dropwise into the flask. The mixture was mixed well and placed in a boiling water bath for 3 mins. The flask was then immediately transferred into the ice bath until the solution was chilled. About $0.6 \mathrm{~mL}$ of ninhydrin reagent $(3 \mathrm{~g} / 100 \mathrm{~mL}$ ninhydrin in $5 \mathrm{~g} / 100 \mathrm{~mL} \mathrm{Na} \mathrm{S}_{2} \mathrm{O}_{5}$ ) was added by carefully allowing the reagent to run down the wall of the flask. The volumetric flask was shaken well and leave at room temperature for 100 mins. The solution in the flask was then adjusted to $25 \mathrm{~mL}$ with concentrated sulphuric acid and mixed by inverting the flask several times. The portion of the solutions was immediately transferred into quartz cells and after 5 mins, the absorbance was measured at $590 \mathrm{~nm}$ by using UV/visible spectrophotometer (UV-160A, SHIMADZU, Kyoto, Japan), with the starch blank as the reference. A calibration curve was prepared with $1 \mathrm{~mL}$ aliquots of standard aqueous solutions containing 10, 20, 30 and 40 $\mu \mathrm{g}$ of propylene glycol per $\mathrm{mL}$. The propylene glycol concentration in the starch was calculated from the standard curve. The factor of 0.7763 was applied to convert micrograms of the glycol to hydroxypropyl group equivalent. The MS was calculated as the equations below:

$$
\begin{aligned}
& \text { Standard curve equation: } \mathrm{y}=0.0001 \mathrm{x} \\
& \mathrm{W}=\frac{\mathrm{C} \times 0.7763 \times 10 \times \mathrm{F}}{\mathrm{w}}
\end{aligned}
$$

Where $\mathrm{W}=$ Amount of hydroxypropylated group in 100 mg of dry starch, $\mathrm{C}=$ amount of propylene glycol $(\mu \mathrm{g} /$ $\mathrm{mL}), \mathrm{F}=$ dilution factor, $\mathrm{w}=$ weight of sample $(\mathrm{mg})$, and $0.7763=$ conversion factor of glycol to hydroxypropyl group equivalent

$$
\text { Molar substitution }=\frac{162 \mathrm{~W}}{5800-57 \mathrm{~W}}
$$




\subsection{Physico-chemical properties of the modified starches}

\subsubsection{Amylose content}

Amylose content of starch was determined according to McGrance et al. (1998). Starches sample (100 mg), were accurately weighed and dissolved by heating in 8 $\mathrm{mL}$ of dimethyl sulfoxide (90\% DMSO) for 15 mins in a water bath at $85^{\circ} \mathrm{C}$. This solution was then cooled and diluted to $25 \mathrm{~mL}$ in a volumetric flask with deionized water. An aliquot $(1 \mathrm{~mL})$ of this solution was then diluted with $50 \mathrm{~mL}$ of water, followed by addition of 5 $\mathrm{mL}$ solution consisting of iodine $(0.0025 \mathrm{~mol} / \mathrm{L})$ in potassium iodide $(0.0065 \mathrm{~mol} / \mathrm{L})$ with mixing. If slight turbidity was observed in the starch sample, the mixture was heated gently with about $5 \mathrm{~mL}$ of water and cooled quickly before adding the remaining water and the iodine reagent. The color of the mixture was allowed to develop for 15 mins after iodine reagent was added. The absorbance of the sample solution was measured at 600 $\mathrm{nm}$ using UV/visible spectrophotometer (UV-160A, SHIMADZU, Kyoto, Japan). A mixture of DMSO and iodine solution was used as the reference. Each sample was run in triplicate. A standard curve with $1 \mathrm{~mL}$ aliquot of mixtures of amylose and amylopectin from potato containing $0 \%, 10 \%, 25 \%, 50 \%, 75 \%$, and $100 \%$ amylose were prepared, measured and plotted. The reagent blank contains all reagents in the same amounts without the sample containing starch.

Standard curve equation: $\mathrm{y}=0.0131 \mathrm{x}+0.1432$

\subsubsection{Fat binding capacity of modified starch}

About $1 \mathrm{~g}$ of starch was placed in a weighted $50 \mathrm{~mL}$ conical bottom centrifuge tube. Corn oil $(5 \mathrm{~mL})$ was added and the sample was dispersed using a vortex mixer for $1 \mathrm{~min}$. The mixture was left at ambient temperature for $30 \mathrm{mins}$ with shaking for $5 \mathrm{~s}$ at every $10 \mathrm{mins}$ interval. The supernatant was decanted and the tube was weighted after centrifugation at $1600 \mathrm{x} g$ for 25 mins (No et al., 2000). The fat binding capacity (FBC) was calculated as followed:

$$
\mathrm{FBC}=\frac{W \mathrm{f}}{W_{\mathrm{o}}} \times 100
$$

Where Wf is the weight of the fat bound $(\mathrm{g})$ and Wo is the initial weight of the sample (g)

\subsection{Characteristics of emulsions}

\subsubsection{Microstructure of the Pickering emulsions}

Microscopic images of the starch granule stabilized emulsions were obtained using Olympus BX41 (Tokyo, Japan) with 10x objective (Plan, Olympus, Tokyo, Japan) $24 \mathrm{hrs}$ after emulsification. The starch granule stabilized emulsions were diluted with the continuous phase and placed on a microscopic slide with a cover glass. The images of the emulsions were taken with a digital camera (JVC model KY-F55BE, Japan) connected to the microscope and processed using an image acquisition software (Olympus Cell A).

\subsubsection{Emulsification index of starch-stabilized emulsions at various starch-to-oil ratios}

Liquid emulsions were by mixing $8 \mathrm{~mL}$ of continuous phase (distilled water containing $0.02 \%$ sodium azide), $4 \mathrm{~mL}$ of dispersed phase (paraffin liquid) and starch at varying amounts $(200 \mathrm{mg}$ of starch $/ \mathrm{mL}$ of oil - $500 \mathrm{mg}$ of $\mathrm{starch} / \mathrm{mL}$ of oil) in a conical bottom centrifuge tube using IKA T-25 ULTRA-TURRAX homogenizer (United States) at $11000 \mathrm{rpm}$ for 4 mins. The emulsifying capacity of the starches was expressed as the volume of the emulsion to the volume of the sample, often referred as emulsification index (EI) within a possible range from 0 to 1 was recorded. A value of 0 represents poor emulsion stability, while a value of 1 represents high emulsion stability (Rayner et al., 2012; Li et al., 2013; Timgren et al., 2013)

\section{Emulsification index $=\frac{\text { Volume of cream layer }}{\text { Total volume of emulsion }}$ \\ 2.4.3 Viscosity of starch-stabilized emulsions}

The viscosity of the starch granule stabilized emulsions (starch concentration of $400 \mathrm{mg} / \mathrm{mL}$ oil) was measured by using a viscometer (Brookfield DV-E Viscometer, United States). The spindle numbers used were 2 and 4 , at the speed of $30 \mathrm{rpm}$.

\subsection{Statistical analysis}

Statistical analysis was conducted using SPSS Statistics Desktop 22.0 (IBM Corporation, USA). Data were expressed as the mean \pm standard deviation from three independent parallel experiments. The analysis of variance (ANOVA) was performed and the significant differences between the means values were determined by using Duncan's multiple range test at $5 \%$ probability level.

\section{Results and discussion}

\subsection{Degree of substitution (DS) of OSA-modified starch}

The efficiency of the OSA modification is commonly determined by measuring the degree of substitution (DS), which is the average number of OS derivatives per glucose unit. Table 1 shows the degree of substitution (DS) of OSA-modified potato, sweet potato and tapioca. OSA-modified potato had significantly higher degree of substitution (DS $=0.0154$ ) than OSAmodified tapioca $(\mathrm{DS}=0.0083)$ and sweet potato $(\mathrm{DS}=$ 0.0081). According to Sweedman et al. (2013), amylose content of the starch has a positive impact on the efficiency of OSA modification. Higher amylose content 
Table 1. Degree of substitution (DS) and molar substitution (MS) of OSA-modified, hydroxypropylated potato, sweet potato and tapioca starch

\begin{tabular}{cccc}
\hline Type of Starch & OSA Substitution (\%) & Degree of Substitution (DS) & Molar Substitution (MS) \\
\hline P & $1.96 \pm 0.48^{\mathrm{b}}$ & $0.0154 \pm 0.0039^{\mathrm{b}}$ & $0.10 \pm 0.02^{\mathrm{a}}$ \\
$\mathrm{S}$ & $1.04 \pm 0.05^{\mathrm{a}}$ & $0.0081 \pm 0.0004^{\mathrm{a}}$ & $0.20 \pm 0.03^{\mathrm{b}}$ \\
$\mathrm{T}$ & $1.06 \pm 0.10^{\mathrm{a}}$ & $0.0083 \pm 0.0008^{\mathrm{a}}$ & $0.11 \pm 0.03^{\mathrm{a}}$ \\
\hline
\end{tabular}

Data are expressed as mean \pm standard deviation where $(n=3)$. Means within a column bearing the different superscript are significantly different at $\mathrm{p}<0.05$ as determined by Duncan's Test. P: Potato starch; S: Sweet potato starch; T: Tapioca starch; OSA: OSA-modified; HP: Hydroxypropylated

indicates that there is a larger amorphous region available for octenyl group substitution. Potato starch (38.30\%, Table 2) which has the highest amylose content among all three tuber native starches had the highest DS. The variation in DS might also due to the insufficient mixing between the water-insoluble OSA and starches phases. During the process of OSA modification, alkaline reagent was added to maintain $\mathrm{pH}$ value but it diluted the OSA-starch mixture at the same time. Since the amount of alkaline reagent used was varied in maintaining the OSA-starch mixture from different starch sources, the DS varied as well. The excess alkaline reagent will also lead to starch gelatinization. When the starch was gelatinized, the modification process stopped, resulting in lower DS value (Wang et al., 2010).

\subsection{Molar substitution (MS) of hydroxypropylated starch}

Table 1 shows the molar substitution (MS) of hydroxypropylated potato, sweet potato and tapioca. During hydroxypropylation, the hydroxyl groups of the tuber starches were substituted with bulky hydroxypropyl group using propylene oxide as etherifying agent (Cui, 2005). Result in Table 1 demonstrated that the MS of SHP (0.20) was significantly higher than both PHP (0.10) and THP (0.11). Higher MS indicated that there was greater collision between tuber starch and propylene oxide, tuber starch was modified to a higher extent and had a higher amount of hydroxypropyl group substituted (Johnson, 1969).

\subsection{Physico-chemical properties of the modified starches}

\subsubsection{Amylose content}

The amylose content of both unmodified and modified potato, sweet potato and tapioca starches is presented in Table 2. Based on the results, the amylose content of all samples reduced significantly after modification.

The amylose contents of both dry heat-treated and hydrothermal treated (mild annealed) starches were significantly lower compared to their native counterparts. According to Lim et al. (2006), when starch is exposed to mild heating ( $<120^{\circ} \mathrm{C}$ for several hours) in the dry state, the physical properties of starch can be changed without any thermal degradation. The amylose of dry heated starch showed mild leaching from starch granules when dispersed in neutral solution but greater in alkaline condition (DMSO). As the mixture cools, the leached amylose chains line up, lock together and form a gel, thus resulted in decreased amylose content. Hydrothermal treatment (mild annealed) involved heating starch in excess water at a temperature above the glass transition but below the gelatinization temperatures, causing changes on the physical reorganization of starch granules. According to a study reported by Krueger et al. (1987), annealing process primarily involves amylose in starch granule and hence, the amylose content of hydrothermal treated starches had lower amylose content than their native. The reduction in amylose content can also be explained as amylose leaching or due to the partial hydrolytic effect of the hydrothermal treatment (Falade and Ayetigbo, 2017).

Table 2. Amylose content and fat binding capacity of unmodified and modified starch

\begin{tabular}{ccc} 
Type of Starch & Amylose Content $(\%)$ & Fat Binding Capacity \\
\hline PC & $38.30 \pm 0.13^{\mathrm{j}}$ & $186.57 \pm 11.31^{\mathrm{a}}$ \\
PHD & $22.68 \pm 1.11^{\mathrm{i}}$ & $189.89 \pm 2.36^{\mathrm{a}}$ \\
PHM & $20.62 \pm 1.41^{\mathrm{h}}$ & $205.40 \pm 2.80^{\mathrm{b}}$ \\
POSA & $19.19 \pm 0.24^{\mathrm{g}}$ & $230.65 \pm 5.83^{\mathrm{cd}}$ \\
PHP & $17.04 \pm 0.72^{\mathrm{f}}$ & $196.81 \pm 2.87^{\mathrm{bc}}$ \\
\hline SC & $17.34 \pm 0.15^{\mathrm{f}}$ & $219.52 \pm 4.14^{\mathrm{bcd}}$ \\
SHD & $7.21 \pm 1.38^{\mathrm{b}}$ & $255.50 \pm 10.47^{\mathrm{ef}}$ \\
SHM & $6.68 \pm 0.06^{\mathrm{b}}$ & $231.46 \pm 4.84^{\mathrm{d}}$ \\
SOSA & $14.25 \pm 0.09^{\mathrm{c}}$ & $261.07 \pm 3.64^{\mathrm{f}}$ \\
SHP & $8.88 \pm 0.27^{\mathrm{de}}$ & $236.48 \pm 9.10^{\mathrm{d}}$ \\
\hline TC & $15.22 \pm 0.11^{\mathrm{e}}$ & $221.42 \pm 6.83^{\mathrm{cd}}$ \\
THD & $6.46 \pm 0.15^{\mathrm{b}}$ & $226.50 \pm 4.89^{\mathrm{cd}}$ \\
THM & $4.71 \pm 0.16^{\mathrm{a}}$ & $224.58 \pm 9.14^{\mathrm{cd}}$ \\
TOSA & $13.70 \pm 0.52^{\mathrm{d}}$ & $247.92 \pm 3.52^{\mathrm{e}}$ \\
THP & $4.06 \pm 0.20^{\mathrm{a}}$ & $239.24 \pm 5.40^{\mathrm{cd}}$ \\
\hline
\end{tabular}

Data are expressed as mean \pm standard deviation where $(n=3)$. Means within a column bearing the different superscript are significantly different at $\mathrm{p}<0.05$ as determined by Duncan's Test. P: Potato starch; S: Sweet potato starch; T: Tapioca starch; C: Without any treatment; HD: Dry heat treated; HM: Hydrothermal treated; OSA: OSA-modified; HP: Hydroxypropylated 
There was a significant decrease in amylose content in all the OSA-modified starch. According to Nadiha et al. (2010), the amorphous region is more accessible than crystalline domains. Since the amorphous region is easily accessible, the substitution of the OS group is expected to occur preferentially at amylose chains, thus distribute and disrupt at this region more than in crystalline domains. This is the main reason that amylose content of OSA-modified starches is lower than their control samples.

During hydroxypropylation of starch, propylene oxide will diffuse into starch granule matrix. The bulky hydroxypropyl group will then substitute onto the amylose of starch. The substitution of this bulky group will change the structure of amylose, thus preventing iodine to bind onto it to form blue color amylose-iodine complex. While there are less amylose-iodine complexes, lower amylose content is obtained from hydroxypropylated starch (Kim et al., 1992), in accordance with our result. According to Wootton and Chaudhry (1981), amylopectin of starch is less susceptible to hydroxypropylation because of its high degree of order.

\subsubsection{Fat binding capacity}

Fat binding capacity was determined to measure the ability of the dry starch to physically bind fat by capillary attraction. The ability of starch to absorb, retain fat and interact with fat is important in emulsion study and also, in food formulations. All modified starches had higher fat binding capacity compared to their control starches. As seen from Table 2, similar trends were seen in all type of tuber starches, where the fat binding capacity of the control starches was the lowest, followed by dry-heated $<$ hydrothermal treated $<$ OSA-modified $<$ hydroxypropylated starches, which had the best ability to bind fat.

Our result is in agreement with Mitchell et al. (1977), Abraham (1993), and Sweedman et al. (2013), who also found increment in fat binding capacity of the starches after thermal modification, OSA-modification and hydroxypropylation, respectively. While Seguchi (1984) reported that dry heating will increase and modify the starch-granule surface proteins, provided sides for oil binding, Lim et al. (2006) claimed that dry heating caused leaching of amylose from starch granules, lead to formation of a complicated matrix encircling the gelatinized granules which in turn bring about the association of oil within the matrix. According to Abraham (1993), the increment in fat binding capacity of hydrothermal treated starch was due to the formation of outer covering with lipophilic nature on the starch granules. After the OSA treatment, starch which is normally hydrophobic will gain hydrophobic octenyl group, that provides more amphiphilic character to the starch, and increase its affinity to oil (Sweedman et al., 2013). On the other hand, Mitchell et al. (1977) reported that the introduction of hydroxypropyl group onto starch through etherification using propylene oxide had increased the hydrophobicity and emulsifying properties of the starch.

\subsection{Characteristics of emulsions}

\subsubsection{Emulsification index of starch-stabilized emulsions at various starch-to-oil ratios}

The starch particle concentration is an important parameter in stabilizing the emulsions. In this study, the stability of oil-in-water $(\mathrm{O} / \mathrm{W})$ emulsions stabilized by native and modified starches was determined and presented in Table 3. The images of the emulsions are displayed in Figure 1 to 5 . As seen from the images, most of the samples consist of three layers: upper layer creamed, emulsion droplets; middle layer, continuous phase and bottom layer, sedimented free starch.

Theoretically, native starches with hydrophilic surface properties have limitations in their application, especially as a stabilizer. However, in this study, native potato starch was found to be able to stabilize oil droplets. According to a study reported by $\mathrm{Li}$ et al. (2013), some native starch granules had the emulsifying ability. The emulsification index of emulsion stabilized using native potato starch increased by $42 \%$ when the mass of added starch increased from 200 to $300 \mathrm{mg} / \mathrm{mL}$ oil. In particle (starch)-stabilized emulsion, the droplet size of emulsions decreases with increasing particle or starch concentration as more particles available to stabilize smaller droplets causing overall droplets to become heavier than the continuous phase (Timgren et al., 2013). However, when the amount of starch added increased to $400 \mathrm{mg} / \mathrm{mL}$ or higher, the emulsification index dropped. While every emulsion system has a limiting drop size, excess starch particles will sediment in the continuous phase when the drop size is reached (Timgren et al., 2013).

The emulsification index of emulsion stabilized by THD increased significantly when the mass of added starch increased from 200 to $400 \mathrm{mg} / \mathrm{mL}$ oil but dropped when the mass of added starch increased to $500 \mathrm{mg} / \mathrm{mL}$ oil. This can be explained by limiting drop size as mentioned above. Both PHD and SHD-stabilized emulsions gained emulsification index value of 1 when $400 \mathrm{mg}$ starch $/ \mathrm{mL}$ oil was added. The emulsification property of THD was different compared to PHD and SHD might due to their hydrophilicity which was varied in different starch granules. There is variation in hydrophilicity between different starches as their degree 

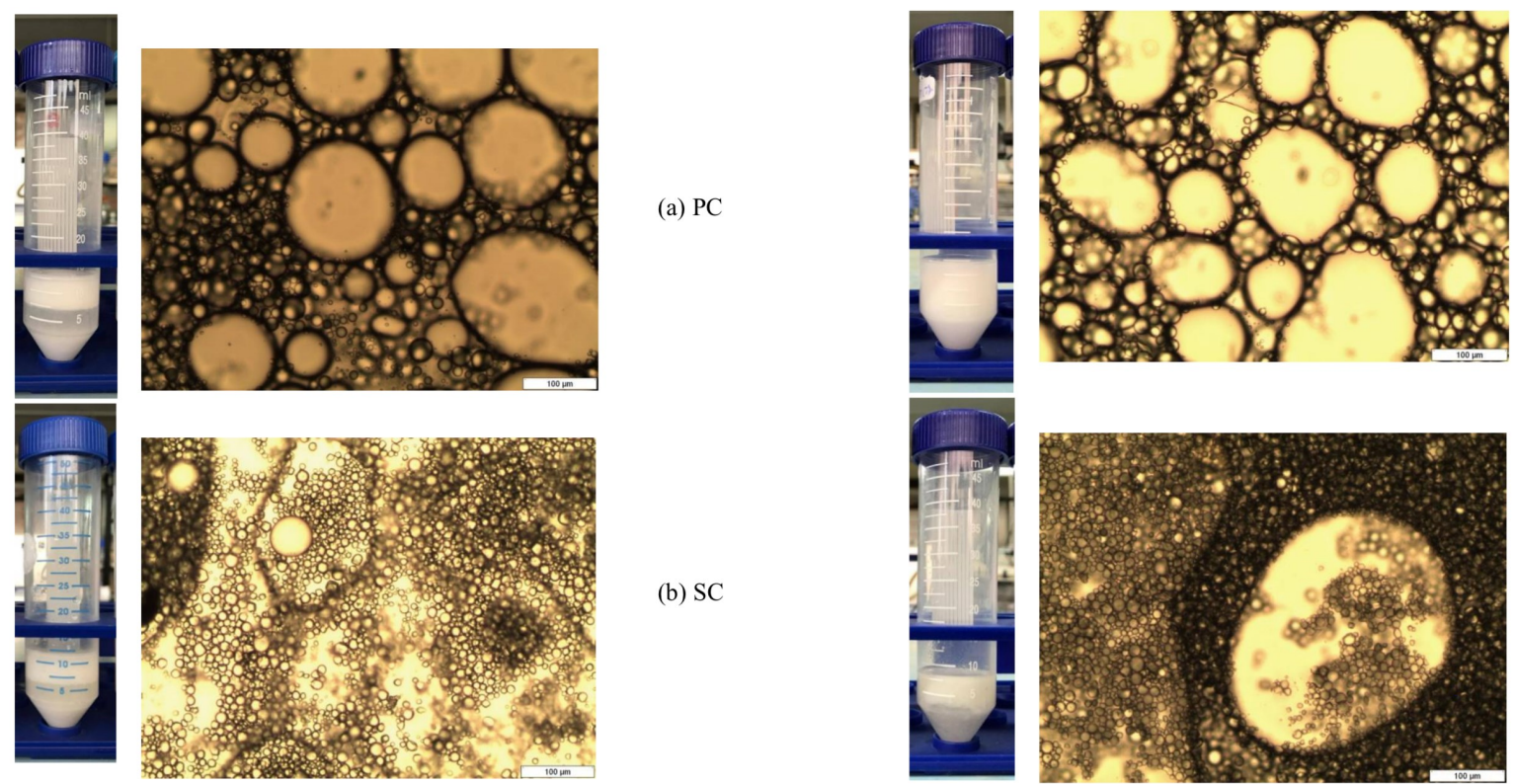

(a) PHD

(a) $\mathrm{PC}$

(b) SC
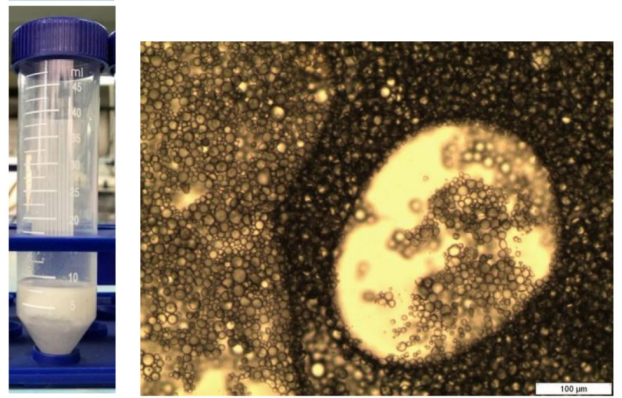

(b) SHD
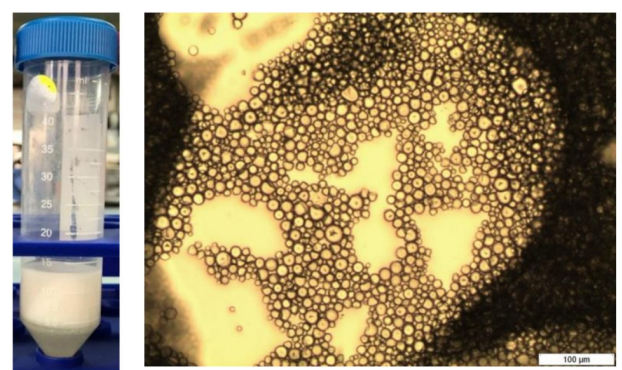

(c) THD
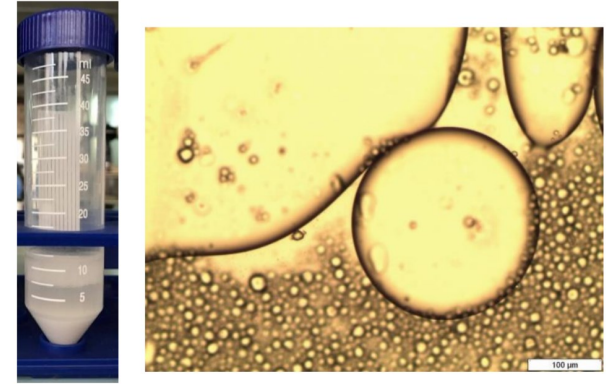

(c) TC

Figure 1. Samples and microscopic images of $\mathrm{O} / \mathrm{W}$ emulsions stabilized by native tuber starches (starch particle concentration $400 \mathrm{mg}$ starch/mL oil) after 1 day of storage.
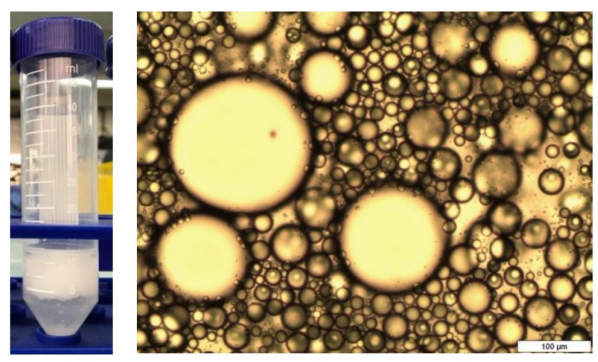

(a) PHM
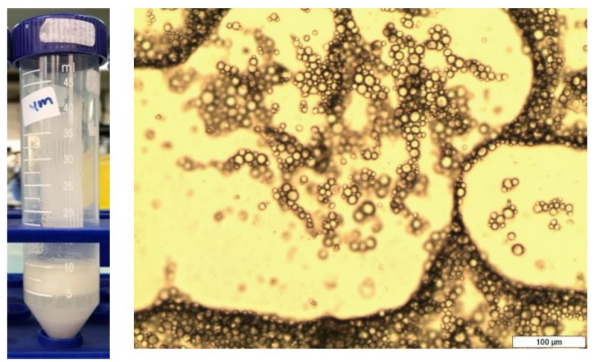

(b) SHM
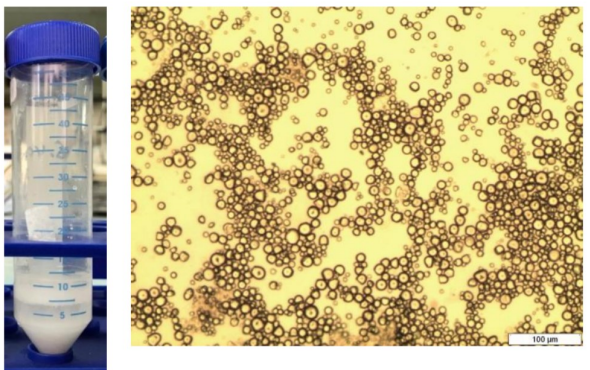

(c) THM

Figure 3. Samples and microscopic images of $\mathrm{O} / \mathrm{W}$ emulsions stabilized by hydrothermal treated tuber starches (starch particle concentration $400 \mathrm{mg}$ starch/mL oil) after 1 day of storage.

Figure 2. Samples and microscopic images of $\mathrm{O} / \mathrm{W}$ emulsions stabilized by dry-heat treated tuber starches (starch particle concentration $400 \mathrm{mg}$ starch/mL oil) after 1 day of storage.
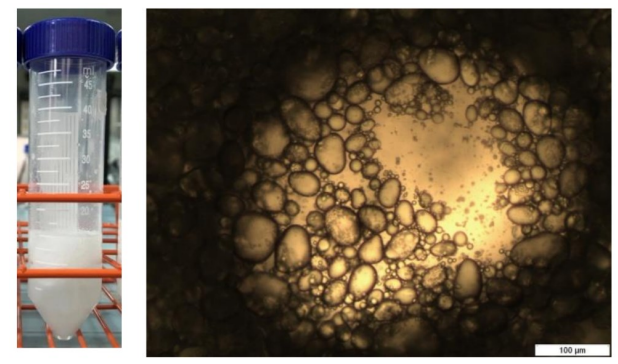

(a) POSA
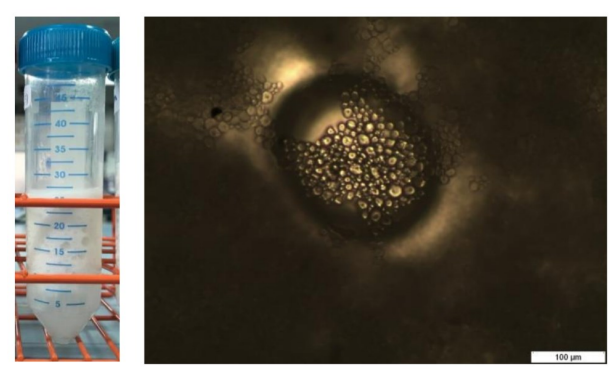

(b) SOSA
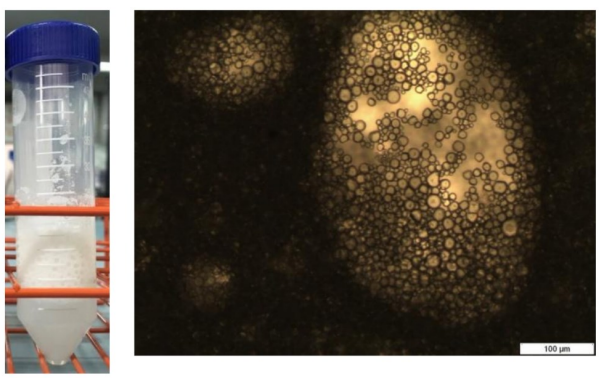

(c) TOSA

Figure 4. Samples and microscopic images of $\mathrm{O} / \mathrm{W}$ emulsions stabilized by OSA-modified tuber starches (starch particle concentration $400 \mathrm{mg} \mathrm{starch} / \mathrm{mL}$ oil) after 1 day of storage.

C 2020 The Authors. Published by Rynnye Lyan Resources 
Table 3. Emulsion index of starch-stabilised emulsions at various starch-to-oil ratios

\begin{tabular}{ccccc}
\hline \multirow{2}{*}{ Type of } & \multicolumn{4}{c}{ Emulsification Index } \\
\cline { 2 - 5 } Starch & \multicolumn{3}{c}{ Amount of Starch Used (mg starch/mL oil $)$} \\
\cline { 2 - 5 } & 200 & 300 & 400 & 500 \\
\hline PC & $0.38 \pm 0.06^{\mathrm{c}}$ & $0.54 \pm 0.32^{\mathrm{fgh}}$ & $0.41 \pm 0.02^{\mathrm{cd}}$ & $0.28 \pm 0.10^{\mathrm{b}}$ \\
PHD & $0.63 \pm 0.03^{\mathrm{ijklm}}$ & $0.69 \pm 0.04^{\mathrm{m}}$ & $1^{\mathrm{p}}$ & $1^{\mathrm{p}}$ \\
PHM & $0.37 \pm 0.03^{\mathrm{c}}$ & $0.59 \pm 0.08^{\mathrm{hijkl}}$ & $0.69 \pm 0.05^{\mathrm{mn}}$ & $0.78 \pm 0.03^{\mathrm{o}}$ \\
POSA & $0.5^{\mathrm{efg}}$ & $0.61 \pm 0.05^{\mathrm{ijklm}}$ & $0.67^{\mathrm{lm}}$ & $0.68 \pm 0.03^{\mathrm{lm}}$ \\
PHP & $0.57 \pm 0.03^{\mathrm{hij}}$ & $0.65 \pm 0.02^{\mathrm{klm}}$ & $1^{\mathrm{p}}$ & $1^{\mathrm{p}}$ \\
\hline SC & $0^{\mathrm{a}}$ & $0^{\mathrm{a}}$ & $0^{\mathrm{a}}$ & $0^{\mathrm{a}}$ \\
SHD & $0.48 \pm 0.04^{\mathrm{ef}}$ & $0.55 \pm 0.04^{\mathrm{ghi}}$ & $0.63 \pm 0.06^{\mathrm{ijklm}}$ & $1^{\mathrm{p}}$ \\
SHM & $0^{\mathrm{a}}$ & $0^{\mathrm{a}}$ & $0^{\mathrm{a}}$ & $0^{\mathrm{a}}$ \\
SOSA & $0.58 \pm 0.07^{\mathrm{hijk}}$ & $0.68 \pm 0.03^{\mathrm{lm}}$ & $0.75 \pm 0.04^{\mathrm{no}}$ & $0.81 \pm 0.02^{\mathrm{o}}$ \\
SHP & $0.46 \pm 0.04^{\mathrm{de}}$ & $0.63 \pm 0.04^{\mathrm{ijklm}}$ & $1^{\mathrm{p}}$ & $1^{\mathrm{p}}$ \\
\hline TC & $0^{\mathrm{a}}$ & $0^{\mathrm{a}}$ & $0^{\mathrm{a}}$ & $0^{\mathrm{a}}$ \\
THD & $0.39 \pm 0.03^{\mathrm{c}}$ & $0.53 \pm 0.06^{\mathrm{fgh}}$ & $0.75 \pm 0.04^{\mathrm{no}}$ & $0.56 \pm 0.05^{\mathrm{ghi}}$ \\
THM & $0^{\mathrm{a}}$ & $0^{\mathrm{a}}$ & $0^{\mathrm{a}}$ & $0^{\mathrm{a}}$ \\
TOSA & $0.48 \pm 0.04^{\mathrm{ef}}$ & $0.63^{\mathrm{ijklm}}$ & $0.65 \pm 0.03^{\mathrm{jklm}}$ & $0.8^{\mathrm{o}}$ \\
THP & $0.52 \pm 0.04^{\mathrm{efgh}}$ & $0.69 \pm 0.05^{\mathrm{mn}}$ & $1^{\mathrm{p}}$ & $1^{\mathrm{p}}$ \\
\hline
\end{tabular}

Data are expressed as mean \pm standard deviation where $(n=3)$. Means within a column bearing the different superscript are significantly different at $\mathrm{p}<0.05$ as determined by Duncan's Test. P: Potato starch; S: Sweet potato starch; T: Tapioca starch; C: Without any treatment; HD: Dry heat treated; HM: Hydrothermal treated; OSA: OSA-modified; HP: Hydroxypropylated
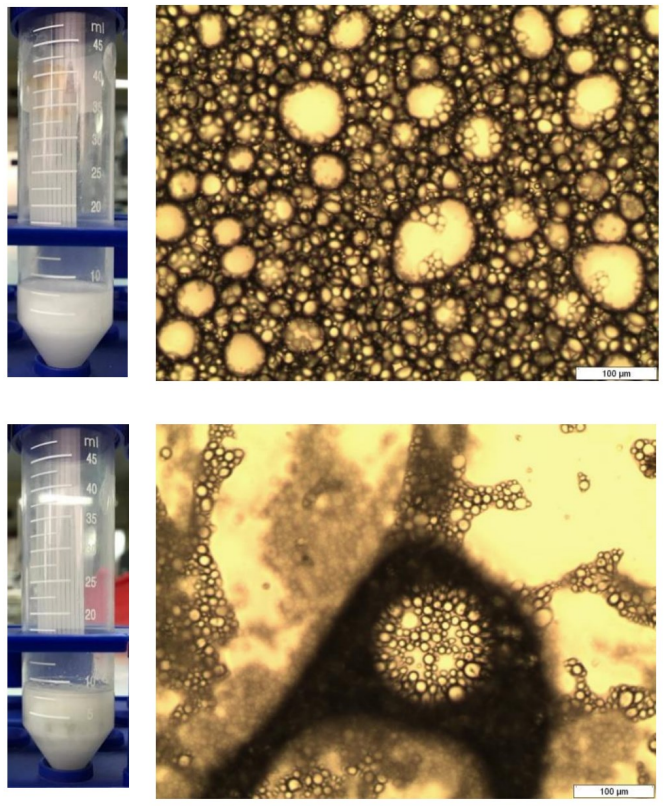

(a) PHP
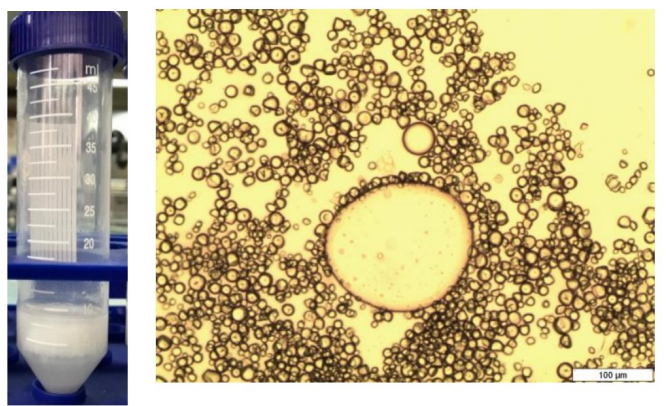

(b) SHP

(c) THP

Figure 5. Samples and microscopic images of $\mathrm{O} / \mathrm{W}$ emulsions stabilized by hydroxypropylated tuber starches (starch particle concentration $400 \mathrm{mg} \mathrm{starch} / \mathrm{mL}$ oil) after 1 day of storage.

of availability of water binding sites will not be the same (Wootton and Bamunuarachchi, 1978). Among all tuber starches, hydrothermal treatment was found increased the emulsification efficiency of potato starch significantly at higher concentration (400 and $500 \mathrm{mg} /$ $\mathrm{mL}$ oil). This might due to the physical and chemical properties of native potato starch, which also had the ability to stabilize emulsion (Li et al., 2013).

All OSA-modified starches were able to stabilize the emulsion. When the mass of added starch increased, the amount of starch attached to the surface of the oil drops increased, thus resulted in an emulsion with higher stability, which can be seen from the increment of emulsification index. Although POSA had highest DS, at starch concentration of $400 \mathrm{mg} / \mathrm{mL}$ oil, SOSA had significantly higher emulsification index than POSA and TOSA. The emulsification properties were independent on DS value. Our results were consistent to studies of Viswanathan, (1999), Bhosale and Singhal (2006) which also found that the emulsification properties of OSA starches were not correlated with their DS value.

When higher starch concentration (400 and $500 \mathrm{mg} /$ $\mathrm{mL}$ oil) was used, all hydroxypropylated starchstabilized emulsions had emulsification index value of 1 . These results are consistent with the previous study reported by Mitchell et al. (1977), who found that hydroxypropyl starch obtained through etherification using propylene oxide had emulsifying properties and was able to act as emulsion stabilizer.

\subsubsection{Microstructure of the Pickering emulsions}

The microstructure and distribution of starch particles in emulsions were observed using an optical microscope. Figure 1 to 5 show the images of the 
emulsions stabilized by native (Figure 1), dry-heat treated (Figure 2), hydrothermal treated (Figure 3), OSAmodified (Figure 4) and hydroxypropylated starches (Figure 5).

All starches particles were found accumulated densely at the oil-water interface except for SC, SHM, TC and THM. Starch granules can be clearly seen on the oil drop surface. Our results are consistent with Rayner et al. (2012), Li et al. (2013), Timgren et al. (2013), and Song et al., (2015), where starch granules were also clearly seen on the drop surface from their micrographs.

\subsubsection{Viscosity of emulsions}

Viscosity of emulsions are depending upon several factors, such as volume concentration of disperse phase, viscosity of dispersed and continuous phase, rate or force of shear, the nature of stabilizer or emulsifying agent used and the particle size of the emulsion (Broughton and Squires, 1938).

As shown in Table 4, all the modified starchstabilized emulsions had a significantly higher viscosity than the emulsions stabilized by their native, respectively. The emulsions stabilized by native starches had the lowest viscosity, followed by emulsions stabilized by hydroxypropylated starches, hydrothermal treated starches, dry-heat treated starches and OSAmodified starches.

Table 4. Viscosity of starch-stabilised emulsions (400 mg starch $/ \mathrm{mL}$ oil)

\begin{tabular}{cc}
\hline Type of Starch & Viscosity (cP) \\
\hline PC & $4.23 \pm 0.12^{\mathrm{ab}}$ \\
PHD & $10.73 \pm 0.25^{\mathrm{f}}$ \\
PHM & $9.40 \pm 0.36^{\text {de }}$ \\
POSA & $40.83 \pm 1.99^{\mathrm{i}}$ \\
PHP & $8.90 \pm 0.53^{\mathrm{d}}$ \\
SC & $3.57 \pm 0.40^{\mathrm{a}}$ \\
SHD & $10.40 \pm 0.26^{\mathrm{ef}}$ \\
SHM & $8.57 \pm 0.06^{\mathrm{d}}$ \\
SOSA & $15.23 \pm 0.49^{\mathrm{g}}$ \\
SHP & $6.33 \pm 0.15^{\mathrm{c}}$ \\
TC & $5.20 \pm 0.35^{\mathrm{b}}$ \\
THD & $10.73 \pm 0.12^{\mathrm{f}}$ \\
THM & $8.77 \pm 0.15^{\mathrm{d}}$ \\
TOSA & $18.93 \pm 1.12^{\mathrm{h}}$ \\
THP & $8.57 \pm 0.46^{\mathrm{d}}$ \\
\hline
\end{tabular}

Data are expressed as mean \pm standard deviation where $(n=3)$. Means within a column bearing the different superscript are significantly different at $\mathrm{p}<0.05$ as determined by Duncan's Test. P: Potato starch; S: Sweet potato starch; T: Tapioca starch; C: Without any treatment; HD: Dry heat treated; HM: Hydrothermal treated; OSA: OSA-modified; HP: Hydroxypropylated.
The viscosity of emulsion formed by POSA showed the highest value, $40.83 \mathrm{cP}$ followed by emulsion formed by TOSA $(18.93 \mathrm{cP})$ and SOSA (15.23 cP). OSAmodification successfully increased the viscosity of potato, sweet potato and tapioca starch emulsion significantly, by $865.25 \%, 326.61 \%$ and $264.04 \%$, respectively. Although OSA-modified starches-stabilized emulsions had significantly higher viscosity $(p<0.05)$, the emulsification index was lower than the hydroxypropylated starch. This might be attributed to the network structure formation through inter-molecular bonding of OSA-modified starch molecules. The network structure increased the viscosity of continuous phase, slowed down the movement of oil droplets and hence reduced the rate of creaming and increased the physical stability of the emulsions (Dokić et al., 2012). This observation could also be related to the formation of weak droplet network structure in the hydroxypropylated starches-stabilized emulsions.

All dry-heat treated starches-stabilized emulsions had almost similar viscosity and significantly higher viscosity compared to those stabilized by unmodified starches. The gel structure of starches became stronger and closer structure after dry heat treatment, thus increasing the viscosity of the emulsions (Sun et al., 2014). All hydrothermal treated starches increased the viscosity of emulsions. The increment on viscosity of oil/ water mixtures that had been homogenized with hydrothermal treated starches might due to the increment of the amount of non-adsorbed particles (starches) present in the aqueous (continuous) phase. The nonadsorbed particles (starches) present able to increase the viscosity of the continuous phase.

\section{Conclusion}

The level of $3 \%$ OSA, $2 \mathrm{~mL}$ of $20 \%$ propylene oxide, and dry heat temperature and time used in starch modification were close to optimal, which allowed the tuber starch granules to accumulate themselves on the surface of oil droplets as well as stabilize the emulsion droplets, creating Pickering emulsion. In this study, OSA modification was more efficient than dry heat treatment, hydrothermal treatment, and hydroxypropylation in providing hydrophobic characteristics to tuber starches. Emulsion stabilized using OSA starches had higher viscosity than other modified starch-stabilized emulsions, indicated stronger droplet network structure formation. Hydrothermal treated starch could not stabilize the mixture of oil and water. Native potato starch was found as able to stabilize emulsion in this study. 


\section{Conflict of Interest}

The authors declare no conflict of interest.

\section{Acknowledgements}

The project was supported by Universiti Sains Malaysia Research Universiti Grant: 1001/ PTEKIND/811339.

\section{References}

Abraham, T.E. (1993). Stabilization of paste viscosity of cassava starch by heat moisture treatment. StarchStärke, 45(4), 131-135. https://doi.org/10.1002/ star. 19930450404

Bhosale, R. and Singhal, R. (2006). Process optimization for the synthesis of octenyl succinyl derivative of waxy corn and amaranth starches. Carbohydrate Polymers, 66(4), 521-527. https://doi.org/10.1016/ j.carbpol.2006.04.007

Broughton, G. and Squires, L. (1938). The viscosity of oil-water emulsions. The Journal of Physical Chemistry, 42(2), 253-263. https://doi.org/10.1021/ j100897a010

Dias, F.F., Tekchandani, H.K. and Mehta, D. (1997). Modified starches and their use by food industry. Indian Food Industry, 16(4), 33-39.

Dokić, L., Krstonošić, V. and Nikolić, I. (2012). Physicochemical characteristics and stability of oilin-water emulsions stabilized by OSA starch. Food Hydrocolloids, 29(1), 185-192. https:// doi.org/10.1016/j.foodhyd.2012.02.008

Falade, K.O. and Ayetigbo, O.E. (2017). Effects of tempering (annealing), acid hydrolysis, low-citric acid substitution on chemical and physicochemical properties of starches of four yam (Dioscorea spp.) cultivars. Journal of Food Science and Technology, 54(6), 1455-1466. https://doi.org/10.1007/s13197017-2568-x

Friberg, S., Larsson, K. and Sjoblom, J. (2003). Food emulsions. USA: CRC Press. https:// doi.org/10.1201/9780203913222

Gelfand, H.H. (1943). The allergenic properties of the vegetable gums: a case of asthma due to tragacanth. Journal of Allergy, 14(3), 203-219. https:// doi.org/10.1016/S0021-8707(43)90640-9

Hannuksela, M., Kousa, M. and Pirilä, V. (1976). Contact sensitivity to emulsifiers. Contact Dermatitis 2(4), 201-204. https://doi.org/10.1111/j.16000536.1976.tb03027.x

Johnson, D.P. (1969). Spectrophotometric determination of the hydroxypropyl group in starch ethers. Analytical Chemistry, 41(6), 859-860. https:// doi.org/10.1021/ac60275a024

Kim, H., Hermansson, A.M. and Eriksson, C. (1992).

Structural characteristics of hydroxypropyl potato starch granules depending on their molar substitution. Starch-Stärke, 44(3), 111-116. https:// doi.org/10.1002/star.19920440307

Krueger, B., Walker, C., Knutson, C. and Inglett, G. (1987). Differential scanning calorimetry of raw and annealed starch isolated from normal and mutant maize genotypes. Cereal Chemistry, 64(3), 187-190.

Lawal, O.S. (2011). Hydroxypropylation of pigeon pea (Cajanus cajan) starch: Preparation, functional characterizations and enzymatic digestibility. $L W T$ Food Science and Technology, 44(3), 771-778. https://doi.org/10.1016/j.lwt.2010.05.025

Li, C., Li, Y., Sun, P. and Yang, C. (2013). Pickering emulsions stabilized by native starch granules. Colloids and Surfaces A: Physicochemical and Engineering Aspects, 431, 142-149. https:// doi.org/10.1016/j.colsurfa.2013.04.025

Lim, H.S., Han, J.-A., BeMiller, J.N. and Lim, S.-T. (2006). Physical modification of waxy maize starch by dry heating with ionic gums. Journal of Applied Glycoscience, 53(4), 281-286. https:// doi.org/10.5458/jag.53.281

McClements, D.J. (2015). Food emulsions: principles, practices, and techniques. USA: CRC press. https:// doi.org/10.1201/b18868

McGrance, S.J., Cornell, H.J. and Rix, C.J. (1998). A simple and rapid colorimetric method for the determination of amylose in starch products. StarchStärke, 50(4), 158-163. https://doi.org/10.1002/ (SICI)1521-379X(199804)50:4<158::AIDSTAR158>3.0.CO;2-7

Mitchell, W.A., Seidel, W.C. and Orozovich, G.E. (1977). Cold water soluble stable bulked starch. Patent No. 4009291. White Plains, New York: General Foods Corportation.

Murray, B.S., Durga, K., Yusoff, A. and Stoyanov, S.D. (2011). Stabilization of foams and emulsions by mixtures of surface active food-grade particles and proteins. Food Hydrocolloids, 25(4), 627-638. https://doi.org/10.1016/j.foodhyd.2010.07.025

Nadiha, M.N., Fazilah, A., Bhat, R. and Karim, A.A. (2010). Comparative susceptibilities of sago, potato and corn starches to alkali treatment. Food Chemistry, 121(4), 1053-1059. https:// doi.org/10.1016/j.foodchem.2010.01.048

No, H.K., Lee, K.S. and Meyers, S.P. (2000). Correlation between physicochemical characteristics and binding capacities of chitosan products. Journal of Food Science, 65(7), 1134-1137. https://doi.org/10.1111/ 
j.1365-2621.2000.tb10252.x

Palm, M., Moneret-Vautrin, D., Kanny, G., DeneryPapini, S. and Fremont, S. (1999). Food allergy to egg and soy lecithins. Allergy, 54(10), 1116-1117. https://doi.org/10.1034/j.1398-9995.1999.00305.x

Pickering, S.U. (1907). Cxcvi. Journal of the Chemical Society, Transactions, 91(0), 2001-2021. https:// doi.org/10.1039/CT9079102001

Rayner, M., Timgren, A., Sjöö, M. and Dejmek, P. (2012). Quinoa starch granules: a candidate for stabilising food-grade Pickering emulsions. Journal of the Science of Food and Agriculture, 92(9), 18411847. https://doi.org/10.1002/jsfa.5610

Sakaguchi, M., Nakayama, T. and Inouye, S. (1996). Food allergy to gelatin in children with systemic immediate-type reactions, including anaphylaxis, to vaccines. Journal of Allergy and Clinical Immunology, 98(6), 1058-1061. https:// doi.org/10.1016/S0091-6749(96)80191-6

Seguchi, M. (1984). Oil-binding ability of heat-treated wheat starch. Cereal Chemistry, 61, 248-250

Song, X., Pei, Y., Qiao, M., Ma, F., Ren, H. and Zhao, Q. (2015). Preparation and characterizations of Pickering emulsions stabilized by hydrophobic starch particles. Food Hydrocolloids, 45, 256-263. https://doi.org/10.1016/j.foodhyd.2014.12.007

Sun, Q., Gong, M., Li, Y. and Xiong, L. (2014). Effect of dry heat treatment on the physicochemical properties and structure of proso millet flour and starch. Carbohydrate Polymers, 110, 128-134. https:// doi.org/10.1016/j.carbpol.2014.03.090

Sweedman, M.C., Tizzotti, M.J., Schäfer, C. and Gilbert, R.G. (2013). Structure and physicochemical properties of octenyl succinic anhydride modified starches: A review. Carbohydrate Polymers, 92(1), 905-920.

https://doi.org/10.1016/ j.carbpol.2012.09.040

Timgren, A., Rayner, M., Dejmek, P., Marku, D. and Sjöö, M. (2013). Emulsion stabilizing capacity of intact starch granules modified by heat treatment or octenyl succinic anhydride. Food Science and Nutrition, 1(2), 157-171. https://doi.org/10.1002/ fsn 3.17

Viswanathan, A. (1999). Effect of degree of substitution of octenyl succinate starch on the emulsification activity on different oil phases. Journal of Environmental Polymer Degradation, 7(4), 191-196. https://doi.org/10.1023/A:1022830715565

Wang, J., Su, L. and Wang, S. (2010). Physicochemical properties of octenyl succinic anhydride-modified potato starch with different degrees of substitution. Journal of the Science of Food and Agriculture, 90
(3), 424-429. https://doi.org/10.1002/jsfa.3832

Wootton, M. and Bamunuarachchi, A. (1978). Water binding capacity of commercial produced native and modified starches. Starch-Stärke, 30(9), 306-309. https://doi.org/10.1002/star.19780300905

Wootton, M. and Chaudhry, M. (1981). In vitro Digestion of Hydroxypropyl Derivatives of Wheat Starch. I. Digestibility and Action Pattern Using Porcine Pancreatic alpha-Amylase. Starch-Stärke, 33 (4), 135-137. https://doi.org/10.1002/ star. 19810330408

Yusoff, A. and Murray, B.S. (2011). Modified starch granules as particle-stabilizers of oil-in-water emulsions. Food Hydrocolloids, 25(1), 42-55. https://doi.org/10.1016/j.foodhyd.2010.05.004 